\title{
Congenital nasal pyriform aperture stenosis: a rare cause of upper airway obstruction in newborn
}

\author{
Diana Pinto Silva, Daniela Ribeiro, Sérgio Vilarinho, Luis Dias
}

Department of ENT, Hospital de Braga, Braga, Portugal

\section{Correspondence to}

Dr Diana Pinto Silva, dianapintosilva@gmail.com

Accepted 5 November 2018

\section{DESCRIPTION}

Congenital nasal pyriform aperture stenosis (CNPAS) is a rare cause of upper airway (UA) obstruction in newborn. Although commonly described as arising from overgrowth of the nasal process of the maxilla, some authors defend that it results from medialisation of normally shaped maxilla. ${ }^{1}$ It is associated with other conditions and midline defects like solitary median maxillary central incisor (SMMCI) and holoprosencephaly. ${ }^{12}$

We report a case of a newborn admitted in neonatal care unit on the second day of life with breathing distress, desaturation and cyanosis, reverted by crying. Ear, nose and throat observation revealed intercostal indrawing, oral breathing and absence of upper lip frenulum. On nasal examination, it was impossible to introduce the slim nasendoscope (Xion EF-N slim with $2.8 \mathrm{~mm}$ of diameter) in the nostrils, achieved after vasoconstriction and dilation with a $2 \mathrm{~mm}$ tube, with confirmation of normal septum and choanal patency. The CT showed pyriform aperture stenosis of $4.7 \mathrm{~mm}$ (measured on axial and coronal levels of the inferior meatus) and SMMCI (figure 1). Initially, conservative treatment and airway measures were applied, but once symptoms persisted, a surgical procedure was realised on the 15 th day of life. A sublabial approach was performed for removal of the lateral nasal wall using a $2.8 \mathrm{~mm}$ diamond burr, widening nasal pyriform aperture. The procedure finished with placement and suturing tubes with $3.5 \mathrm{~mm}$ in each nostril (figure 2), removed after

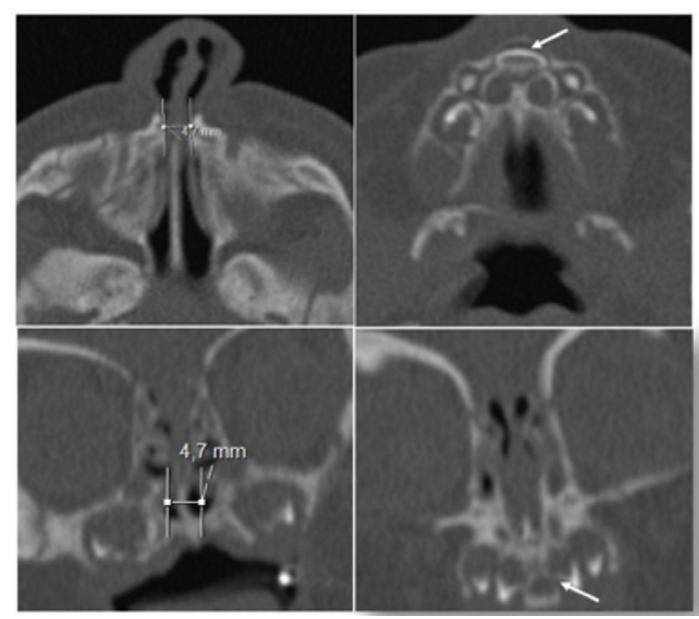

Figure 1 CT images (axial and coronal planes) with findings of pyriform aperture stenosis of $4.7 \mathrm{~mm}$ (measured at the level of the nasal inferior meatus) and solitary median maxillary central incisor (arrows).

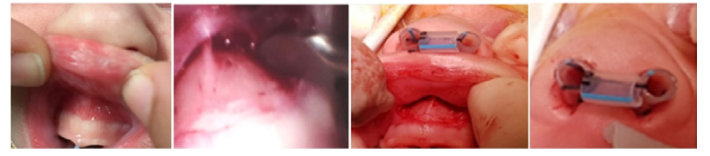

Figure 2 Sublabial surgical approach. Exposure of the sublabial mucosa, mucosal incision to reach pyriform aperture stenosis and nasal process of maxilla, closure of the mucosa and placement of $3.5 \mathrm{~mm}$ tubes in the nostrils.

2 weeks, without complications. After 2 months, she experienced weight gain and had no feeding or breathing problems.

CNPAS is a rare condition of breathing distress in newborns. The diagnosis is suggested by physical examination due to failure to pass a nasogastric tube or slim nasendoscope within the first $1 \mathrm{~cm}$ of the nostrils and confirmed by CT findings of pyriform aperture width $<11 \mathrm{~mm}$ (measured on an axial level of the inferior meatus) in a full-term neonate. ${ }^{12}$ The main differential diagnose is choanal atresia that is a congenital narrowing of the posterior nasal airway by a bony or membranous septum. ${ }^{12}$ First-line treatment is based on airway measures such as nasal saline solutions, decongestants or intranasal steroids, tried at least for 15 days. ${ }^{1}$ Surgery is indicated towards conservative management failure or clinical presentation with apnoeic episodes, cyanosis, poor growth and failure to thrive. ${ }^{13}$ Current surgical procedure is sublabial approach with drill of the lateral nasal wall, that is effective but may involve complications such as injuries to lacrimal system and to the tooth buds. ${ }^{13}$ Postoperative nasal stenting is the norm, although the optimal duration for stenting remains a matter of debate. ${ }^{3}$ Novel and less-invasive treatments, such as rapid maxillary expansion, allows widening of the nasal base, leading to reduction in nasal airway resistance, having shown good results and may become standard treatment for CNAPS in

\section{Learning points}

- Upper airway (UA) obstruction in newborn should be carefully addressed.

- Congenital nasal pyriform aperture stenosis must be kept in mind as a rare but treatable cause of UA obstruction in neonates.

- The main goals are establishment of nasal patency, screen and management of other associated conditions, achieved with multidisciplinary teams. 
the future. ${ }^{1}$ Short and long follow-up should be done carefully by a multidisciplinary team.

CNPAS should be reminded in newborn with UA obstruction. Attempted diagnosis provides adequate management and treatment with re-establishment of nasal patency in first days of life.

Acknowledgements The authors would like to their colleagues and guidance counsellor, ENT Department and Hospital and the parents of the child.

Contributors DPS: data collection, article conception and writing the draft. DR: conception and design, guidance in data collection, analysis and interpretation of data. SV: discuss conduct and planning. LD: teaching and research.

Funding The authors have not declared a specific grant for this research from any funding agency in the public, commercial or not-for-profit sectors.
Competing interests Not declared

Patient consent Parental/guardian consent obtained.

Provenance and peer review Not commissioned; externally peer reviewed.

\section{REFERENCES}

1 Collares MV, Tovo AH, Duarte DW, et al. Novel treatment of neonates with congenital nasal pyriform aperture stenosis. Laryngoscope 2015;125:2816-9.

2 Yang S, Orta P, Renk EM, et al. Congenital nasal pyriform aperture stenosis in association with solitary median maxillary central incisor: unique radiologic features. Radiol Case Rep 2016;11:178-81.

3 Wood J, Van Der Meer G. Surgery for congenital nasal pyriform aperture stenosis (CNPAS). Open access atlas of Otolaryngology, Head and Neck operative surgery. 2017 www.entdev.uct.ac.za.

Copyright 2018 BMJ Publishing Group. All rights reserved. For permission to reuse any of this content visit https://www.bmj.com/company/products-services/rights-and-licensing/permissions/

BMJ Case Report Fellows may re-use this article for personal use and teaching without any further permission.

Become a Fellow of BMJ Case Reports today and you can:

- Submit as many cases as you like

- Enjoy fast sympathetic peer review and rapid publication of accepted articles

- Access all the published articles

- Re-use any of the published material for personal use and teaching without further permission

For information on Institutional Fellowships contact consortiasales@bmjgroup.com

Visit casereports.bmj.com for more articles like this and to become a Fellow 